\title{
Políptico hispano-alemán con fondo de Europa en ruinas. Algunas notas sobre Alemania Occidental como referente cultural en España tras la Segunda Guerra Mundial ${ }^{1}$
}

\author{
Carlos Sanz Díaz ${ }^{2}$
}

Resumen. Este artículo explora, con especial referencia a testimonios autobiográficos, algunos aspectos del papel que jugó Alemania Occidental como referente cultural para España después de la Segunda Guerra Mundial. Durante este periodo, la cultura alemana fue la puerta por la que una generación de jóvenes españoles formados en universidades de aquel país accedió a una cultura europea crítica. Al mismo tiempo, en la sociedad española distintos autores trataban de dotar de inteligibilidad a la experiencia alemania de posguerra.

Palabras clave: Alemania Occidental; España; Cultura; Universidad; Postguerra; Segunda Guerra Mundial.

\section{[en] Spanish-German Polyptych on a Background of Europe in Ruins. Some notes on West Germany as a cultural reference in Spain after World War II}

\begin{abstract}
This article explores, with special reference to autobiographical testimonies, some aspects of the role played by West Germany as a cultural reference point for Spain after World War II. During this period, German culture was the door through which a generation of Spanish young people trained in German universities gained access to a critical European culture. At the same time, different Spanish authors sought to provide intelligibility to the experience of postwar Germany.
\end{abstract}

Keywords: West Germany; Spain; Culture; University; Postwar; World War II.

Sumario. Introducción. 1. Germania docet. 2. Germaniam. Intellegere. 3. Coda.

Cómo citar: Sanz Díaz, C. (2016). Políptico hispano-alemán con fondo de Europa en ruinas. Algunas notas sobre Alemania Occidental como referente cultural en España tras la Segunda Guerra Mundial. Cuadernos de Historia Contemporánea 38, Núm. Esp. 333-344.

1 Este trabajo forma parte del proyecto de investigación HAR2014-58695-R, "La modernización del sistema educativo y científico español en su dimensión internacional (1953-1986)", financiado por el Ministerio de Economía y Competitividad.

$2 \quad$ Universidad Complutense de Madrid (España) carlos.sanz@ghis.ucm.es 


\section{Introducción}

"Pienso que es en Berlín, precisamente en Berlín, donde hay que hablar de Europa". Lo decía Ortega y Gasset el 7 de septiembre de 1949 ante miles de estudiantes que abarrotaban las aulas mayores -fue necesario instalar altavoces- de la Universidad Libre de Berlín, la institución creada menos de un año antes en el sector americano de la ciudad sometida a ocupación militar cuatripartita. ${ }^{3}$ La conferencia berlinesa, Meditación de Europa, fue el punto culminante de un triunfal periplo académico con escalas previas en Darmstadt y Stuttgart, donde el filósofo madrileño había hablado ante públicos igualmente numerosos y entusiastas. ${ }^{4}$ Era también la expresión de un fenómeno más amplio: el reencuentro y el restablecimiento de contactos culturales y académicos entre España y Alemania, después de que el curso de la Segunda Guerra Mundial impusiera a finales de 1944 una incomunicación casi total entre los dos países.

La posición desde la que regresó Ortega, la del maestro consagrado -contaba entonces sesenta y seis años-, fue excepcional entre los españoles que comenzaron a llegar a las universidades alemanas en estos años buscando la conexión no solo con la cultura de aquel país, sino con la gran corriente de la cultura viva de la Europa de posguerra, cuyo rumor apenas resultaba audible en la España de la dictadura y el nacionalcatolicismo. Estudiantes, en su mayoría apenas en la veintena, compartían la atracción por el prestigio de la ciencia y la cultura alemanas, que en España se había mantenido intacto a pesar del desastre moral y material del nacionalsocialismo y la guerra. "Por eso", apostillaba Ortega en 1949, "a esta Alemania política y económicamente triturada, con sus ciudades desventradas, con sus ríos despontados, volvemos a ir todos. ¿A qué? Pues ¿a qué va a ser? A aprender". ${ }^{5}$

\section{Germania docet}

En medio de las ruinas materiales en que se desenvolvía la vida cotidiana de la Alemania de la posguerra, Germania docet era una fórmula que conservaba su vigencia para una parte importante de la ciencia y la cultura española de la segunda mitad de los años cuarenta y la década de los cincuenta. Y ello a pesar de que, en los primeros años tras la derrota, la Alemania ocupada y dividida se eclipsara culturalmente, hasta el punto de que el diplomático Miguel de Lojendio, enviado por el gobierno español a las zonas occidentales del país en la primavera de 1946, temiera por su desaparición definitiva como entidad histórica y baluarte (militar, pero también cultural) contra la penetración del comunismo ruso. En un informe enviado a Madrid en junio de aquel año, Lojendio retrataba un país de ruinas donde "el aire frío del invierno, sin obstáculo y sin trabas", circulaba "en sus casas deshechas" al igual que a "esta Europa dolorida de la guerra" la atravesaba "el soplo afilado del frío aire del Este".

3 ORTEGA Y GASSET, José: Meditación de Europa. Madrid, Revista de Occidente, 1960, p. 21. [Cap. "De Europa Meditatio Quaedam", conferencia pronunciada en Berlín en 1949, revisada y ampliada para esta edición; y cuyo tema retomó en la conferencia pronunciada en Munich en 1953 "Gibt es ein europäisches Kulturbewusstsein? (“¿Hay una conciencia europea?), publicada bajo el título Europäische Kultur und europäische Völker ("Cultura europea y pueblos europeos"), Stuttgart, Deutsche Verlags-Anstalt, 1954].

4 GRACIA, Jordi: José Ortega y Gasset, Madrid, Taurus, 2014, pp. 616-617, 619 y 621.

5 ORTEGA Y GASSET, José: Meditación de Europa ..., p. 94. 
Continuaba el diplomático español: "La guerra, y sus dolorosas consecuencias, ha hecho objeto, en Alemania, a la cultura europea de una tremenda amputación: con ella, ha desaparecido la cultura alemana, cultura occidental, cultura de vanguardia, punta de flecha, ofensiva y defensiva entre el Occidente y el Oriente". 6

Más de dos años tardarían aún en restablecer el Estado español y la Alemania occidental las relaciones consulares, primero, y diplomáticas después, y en hacer posible con ello la reanudación de los contactos académicos sobre una base institucional bilateral. El camino para esto último lo preparó en gran medida un diplomático joven, Gonzalo Fernández de la Mora, quien andando el tiempo llegaría a ser maître à penser del conservadurismo español. ${ }^{7}$ Obsesionado por ser enviado a Alemania para aprender el idioma, que él consideraba la puerta de entrada a uno de los pilares fundamentales de la cultura europea, Fernández de la Mora consiguió en octubre de 1949 ser designado, a los veinticinco años, vicecónsul adjunto de España en Frankfurt am Main, la arrasada capital de la zona norteamericana de ocupación. No era un gran destino desde el punto de vista profesional, dado que el país ni siquiera era soberano, pero daba igual. "Mis idiomas eran librescos", escribiría mucho más tarde, "como mi visión del mundo transpirenaico. Ahora, al corazón de la madre Europa, a la patria de Kant y de Beethoven. Goethe casi siempre insufrible". 8 Durante dos años, en Frankfurt y como encargado de negocios en la representación española en Bonn hasta 1951, Fernández de la Mora inició los contactos necesarios con universidades, instituciones y centros académicos para franquear a otros jóvenes españoles el camino a Alemania.

Dado el ascendente de la Alemania sobre la dictadura franquista en los años cuarenta, era inevitable -como han señalado C. Kent y T.K. Wolber-, que el gobierno español prefiriera enviar a sus futuros líderes intelectuales a la República Federal, conservadora y anticomunista de Adenuaer, aprovechando las becas que comenzaron a ofrecer las universidades e instituciones religiosas de aquel país. Inevitable era igualmente que la apertura de horizontes vitales e intelectuales que la "experiencia alemana" aportó a estos jóvenes españoles acabara llevándoles otros países -Inglaterra, Francia, Italia... - y a asimilar las corrientes de la cultura europea crítica, incluyendo el marxismo y el existencialismo de cuño francés. ${ }^{9}$ A este respecto tiene 1950 cierto carácter de annus mirabilis desde el momento en que en aquel verano coincidieron en un curso de lengua y cultura alemanas en Heidelberg el médico socialista y "posfreudiano", después también novelista, Luis Martín Santos (24 años), un Joan Reventós recién licenciado en Derecho (22 años), el filósofo "premarxista" Manuel Sacristán (24 años), el historiador catalanista, posteriormente sacerdote, Hilari Raguer, y el poeta y después editor Carlos Barral (22 años). ${ }^{10}$

6 Informe sobre Alemania enviado por Miguel de Lojendio al ministro de Asuntos Exteriores, 21 de junio de 1946; remitido al Palacio de Santa Cruz como anexo al despacho personal y reservado núm. 601 de Miguel Mateu, embajador de España en París, 22 de junio de 1946, Archivo del Ministerio de Asuntos Exteriores y Cooperación (AMAEC) 2304/4.

7 Para su biografía véase GONZÁLEZ CUEVAS, Pedro Carlos: La razón conservadora: Gonzalo Fernández de la Mora, una biografia político-intelectual. Madrid, Biblioteca Nueva, 2015.

8 FERNÁNDEZ DE LA MORA, Gonzalo: Río arriba. Memorias, Barcelona, Planeta, 1995, p. 73.

9 KENT, Conrad y WOLBER, Thomas: "Introduction", en KENT, Conrad, WOLBER, Thomas K. y HEWITT, Camron M.K. (eds.), The Lion and the Eagle. Interdisciplinary Essays on German-Spanish Relations over the Centuries, New York, Berghahn Books, 2000, pp. 1-44, esp. 30.

10 Las denominaciones entrecomilladas son de BARRAL, Carlos: Años de penitencia. Barcelona, Tusquets, 2001, p. 342 . 
Barral ha transmitido en sus memorias impresiones muy vívidas de esta su primera salida al extranjero: en la frontera franco-alemana los funcionarios alemanes de aduanas "conservaban inmarchito el estilo de la Gestapo", en las carreteras de "aquella Germania de comunicaciones todavía escasas (...) el auto-stop atravesaba un periodo de esplendor", en las "maltrechas ciudades importantes" la vida "seguía siendo durísima", los alojamientos escaseaban hasta el punto de que un búnker antiaéreo hacía las veces de hotel, y la posguerra era en todas partes "tan evidente, reciente, diría, al cabo de cuatro largos años" que las diferencias con España se disipaban: "habíamos, como quien dice, acampado en un país en régimen semicarcelario, que en muchos aspectos debía de recordar las incomodidades de aquel del que habíamos salido, básicamente para respirar"11.

El panorama de la Alemania urbana de 1950 era desolador: "Gris de cemento destripado, fachadas inútilmente erguidas en el vacío, calles serpenteantes como senderos entre campos de escombros, zanjas y pasarelas resonantes". ${ }^{12}$ Pero no menos descorazonador era el paisaje humano que describió Barral: "en la mayoría era demasiado aparente un cierto aire de rencor y culpa, algo así como una mueca de excusa y complicidad que se interpretaba muy bien en las avenidas en ruinas, en las calles de las ciudades casi íntegramente aniquiladas, calles o caminos que atravesaban interminables cercados de ruinas y cascotes". ${ }^{13} \mathrm{Y}$ a pesar de todo, a través de esas gentes y esas ruinas el joven Barral estaba tomando contacto no con Alemania únicamente sino con la cultura de todo el Viejo Continente:

\begin{abstract}
"Hablando en las tabernas, buscando posada, mi alemán escolar resucitaba, el país se me iba volviendo familiar y poco a poco el paisaje humano se me iba haciendo inteligible. Y el paisaje tout court que en Heidelberg, de momento, me había parecido enormemente escenográfico, irremisiblemente cocinado por el Romanticismo, se me iba desnudando, me iba dejando entrever la piel de Europa". ${ }^{14}$
\end{abstract}

La biografía de algunos estudiantes de aquel grupo, que incluía además ingenieros y diplomados en carreras técnicas, no volvería a pasar por Alemania nunca más. Otros se reencontraron una o varias veces con el país, a veces con efectos decisivos para sus trayectorias individuales y para la cultura española. Fue el caso de Manuel Sacristán, que regresó de 1954 a 1956 para estudiar lógica matemática con Heinrich Scholz en el Instituto de Lógica Matemática e Investigación de Fundamentos de la Universidad de Münster a la vez que perfeccionaba su conocimiento de la "superlengua", como denominaba al idioma alemán. ${ }^{15}$ También en Münster, según refiere J.R. Capella, en reuniones dirigidas por un trabajador alemán a las que Sacristán acudía con otros estudiantes españoles e italianos, entró en contacto con la militancia comunista y amplió sus lecturas de teoría marxista, cuyos autores (de Marx y Engels a Lukács, Gramsci, Adorno y Marcuse) conoció de primera mano y tradujo en muchos casos. De Alemania regresó en 1956 un Manuel Sacristán que trabaja como profesor no numerario de las Facultades de Filosofía y Letras y Económicas de la Universidad

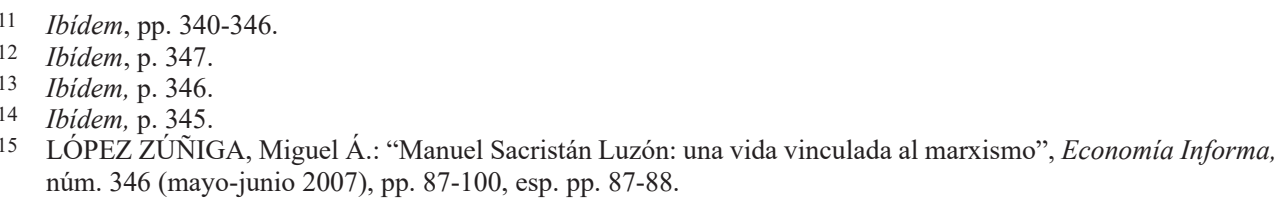


de Barcelona, a la vez que se integra a la militancia clandestina como miembro del comité de dirección del Partido Comunista de España y del Partido Socialista Unificado de Cataluña. ${ }^{16}$

Igualmente transformadora fue la experiencia alemana para José María Carandell i Robusté, periodista y ensayista que en los primeros años cincuenta -a sus veintipocos años- amplió sus estudios de Filosofía de la Universidad de Barcelona en Hamburgo y Múnich, y que conocería en aquel país en 1957 a la que fue su esposa, la pintora Christa Gottschweski. Carandell vivió varios años en Alemania y se situó en la España de los años sesenta y setenta como un analista y portavoz de la cultura y la literatura alemana, con influyentes ensayos dedicados a escritores como Peter Weiss o Hermann Hesse. ${ }^{17}$

No menos importante fue la doble experiencia alemana -bélica y académica- del psicólogo José Luis Pinillos, uno de los padres de la psicología moderna en España, ex combatiente de la División Azul, y becado tras la guerra por el Consejo Superior de Investigaciones Científicas en la Universidad de Bonn, en cuyo Departamento de Psicología Experimental se integró en 1950, a los treinta y un años. Pinillos completó estudios en Gran Bretaña entre 1951 y 1953 y regresaría a la universidad española en 1954, para conseguir años después la cátedra de Psicología Experimental, en Valencia en 1961 y en Madrid en 1966. A partir de sus observaciones en su etapa formativa en Alemania, Pinillos elaboró una serie de notas sobre la psicología alemana que la revista del CSIC Arbor publicó en 1950 y sobre las que volveremos en breve.

En el mantenimiento del vínculo intelectual con Alemania desempeñó un papel crucial Santiago Montero Díaz, un catedrático relativamente joven (había nacido en 1911) de Historia de la Facultad de Filosofía y Letras de la Universidad de Madrid quien, como señala X.M. Núñez Seixas, transmitió su "notable germanofilia intelectual" a numerosos estudiantes y discípulos. Algunos de sus doctorandos fueron encaminados a realizar estudios de doctorado o estancias postdoctorales en los centros académicos de la República Federal de Alemania, "uno de los destinos académicos que su director de tesis seguía privilegiando para sus discípulos"18. Entre ellos se contaba el poeta y filólogo Gonzalo Sobejano, quien marchó a Heidelberg en 1951 y amplió conocimientos en Mainz y Colonia antes de partir en 1963 a Estados Unidos. También el filósofo y filólogo Emilio Lledó, formado igualmente en Heidelberg entre 1952 y 1962 (con estancias intermedias en España) al lado de Hans-Georg Gadamer, Karl Löwith y Otto Regenbogen. O el historiador Juan José Carreras Ares, ayudante de cátedra de Montero Díaz entre 1950 y 1954 que marchó este último año, recién doctorado, a Heidelberg para trabajar hasta 1958 como profesor de Historia y Cultura española de la Escuela de Traductores y, entre 1959 y 1966, como lector y colaborador científico del Seminario de Historia de la Universidad.

La estancia en Heidelberg, como ocurrió con tantos otros, transformó la trayectoria vital y académica de Carreras Ares quien, bajo el magisterio de Werner Conze (director junto con Fritz Ernst del Historisches Seminar), se empapó de los debates y avances en historia social y económica que estaban a la orden del día en la universi-

16 CAPELLA, Juan-Ramón: La práctica de Manuel Sacristán. Una biografia política. Madrid, Trotta, 2005; véase también Ídem, "Manuel Sacristán. Esbozo de una biografía política", en: LÓPEZ AMAL, S. y VÁZQUEZ ÁlVAREZ, I. (eds.): El legado de un maestro. Homenaje a Manuel Sacristán, Madrid, FIM, 2007, pp. 31-39.

17 KENT, Conrad y WOLBER, Thomas: "Introduction", p. 30.

18 NÚÑ̃Z SEIXAS, Xosé-Manoel: La sombra del César. Santiago Montero Díaz, una biografia entre la nación y la revolución. Granada, Comares, 2012, p. 186. 
dad alemana, así como de la hermenéutica de Gadamer y la filosofía de la historia de Karl Löwith. En Heidelberg viró Carreras su especialización hacia un contemporaneísmo renovador que después traería a España al reincorporarse en 1965 al mundo académico español. ${ }^{19}$ Lledó escribiría tiempo después sobre la común experiencia alemana de Carreras Ares y él mismo:

"Juan José y yo vivimos la experiencia alemana desde nuestra propia historia de estudiantes en un país del que habíamos querido salir, porque había dejado de ser nuestro país, y de una Universidad en cuya estructura intuíamos la incompetencia, la malversación de los caudales culturales, de la inteligencia y, de paso, la manipulación de nuestra gente, de nuestros conciudadanos.

Creo que, más o menos conscientemente, era esto lo que nos llevó, a comienzos de los años cincuenta, a emprender nuestra peculiar aventura". ${ }^{20}$

Sería también una experiencia alemana, una estancia de cuatro meses de 1961 en la Universidad de Freiburg am Breisgau trabajando con el hispanista Johannes Vincke de la Facultad de Teología Católica y con Karl Deutinger del Institut für Caritas Wissenschaft, la que -a juicio de I. Peiró- determinó el tránsito de otro historiador, José María Jover, al contemporaneísmo y al cultivo de una historia de las relaciones internacionales inspirada, entre otros referentes, por la obra del archivero e historiador de Marburgo Ludwig Dehio. ${ }^{21}$

Pero la atracción de la cultura y la universidad alemanas no se limitó al ámbito de las humanidades y las ciencias sociales. En el campo del Derecho, generaciones de estudiantes españoles ampliaron estudios en Alemania como paso necesario para acceder a las cátedras o progresar profesionalmente, mientras en España el jurista más destacado del III Reich, Carl Schmitt, gozaba de un enorme prestigio y de la más alta estima en el seno del franquismo. ${ }^{22} \mathrm{La}$ formación de científicos españoles en Alemania, en especial en campos como la física nuclear, se reanudó con cierta fuerza tan pronto fue posible restablecer los contactos interrumpidos con la guerra. ${ }^{23}$ En la coyuntura de parcial aislamiento que compartieron coyunturalmente España y

19 ACERETE DE LA CORTE, Eduardo: “España medieval, Alemania contemporánea. El tránsito historiográfico de Juan José Carreras Ares”, en Juan José Carreras Ares, De la España medieval a la Alemania contemporánea. Primeros escritos (1953-1968), Zaragoza, Instituto "Fernando el Católico"(CSIC) y Excma. Diputación de Zaragoza, 2014 (edición de Eduardo Acerete de la Corte), pp. V-CIX. Véase también FORCADELL ÁLVAREZ, Carlos (ed.), Razones de historiador. Magisterio y presencia de Juan José Carreras, Zaragoza, Institución "Fernando el Católico", 2009.

20 LLEDÓ, Emilio: "Hacia una Universidad democrática", Materiales, 7 (enero-febrero, 1978), p. 36, apud ACERETE DE LA CORTE, Eduardo: "España medieval...”, p. XLVI.

21 PEIRÓ, Ignacio: "Las metamorfosis de un historiador: el tránsito hacia el contemporaneísmo de José María Jover Zamora", Revista de Historia Jerónimo Zurita, núm. 82 (2007), pp. 175-234.

22 LÓPEZ GARCÍA, José Antonio: "La presencia de Carl Schmitt en España", Revista de Estudios Políticos (Nueva Época), núm. 91 (1996), pp. 139-186; SARALEGUI, Miguel: Carl Schmitt, pensador español. Madrid, Trotta, 2016.

23 PRESAS I PUIG, Albert: "La inmediata posguerra y la relación científica y técnica con Alemania", en ROMERO DE PABLOS, Ana y SANTESMASES NAVARRO DE PALENCIA, María Jesús (coord.): Cien años de política cientifica en España, Bilbao, Fundación BBVA, 2008, pp. 173-210; ROMERO, Ana: "Un viaje de José María Otero Navascués. Los inicios de la investigación nuclear en España”, Arbor, vol. 167, núm. 659660 (2000), pp. 509-525. Véase con carácter general REBOK, Sandra (ed.): Traspasar fronteras. Un siglo de intercambio cientifico entre España y Alemania / Über Grenzen hinaus. Ein Jahrhundert deutsch-spanische Wissenschaftsbeziehungen. Madrid: Consejo Superior de Investigaciones Científicas / Deutscher Akademischer Austauschdienst, 2010. 
la RFA hasta mediados de los años cincuenta, Alemania fue en definitiva un destino particularmente atractivo y accesible para varias cohortes de universitarios españoles.

\section{Germaniam intellegere}

A pesar de la relativa familiaridad de unos pocos intelectuales y universitarios españoles con el mundo alemán, para una mayoría de españoles Alemania y su destino histórico reciente tenían, a comienzos de los años cincuenta, algo de enigma que debe ser desentrañado. La información censurada y distorsionada que habían recibido durante la Segunda Guerra Mundial y la posguerra les había preparado especialmente mal para hacerse cargo de la magnitud de la derrota alemana y para comprender el significado histórico del nuevo Estado germano occidental.

Como ha señalado B. Aschmann, la nostalgia fascista y la desconfianza ante la presuntamente débil democracia representada por la República Federal de Alemania teñían las imágenes españolas sobre Alemania tras la guerra. ${ }^{24}$ Según constataría el embajador alemán en Madrid Wolfgang von Welck a finales de los años cincuenta, la admiración de los españoles por las hazañas bélicas del III Reich no se había extinguido a pesar de la derrota alemana. ${ }^{25}$ Aunque en 1948 se había publicado en Madrid el clarificador ensayo de Karl Jaspers El problema de la culpa basado en sus conferencias de Heidelberg de 1946, en España la rendición incondicional y la división de Alemania continuaron siendo vistas como decisiones erróneas e injustas, mientras los juicios de Núremberg se consideraban por lo general como una venganza de los aliados sobre los vencidos. ${ }^{26}$

El propio paisaje humano de una parte de la colonia alemana mantenía vivos los vínculos con el pasado, no en vano - como ha mostrado C. Collado Seidel- en España habían hallado refugio más de un centenar de nazis más o menos prominentes que, salvo escasas excepciones, trataban de pasar desapercibidos para evitar ser entregados a las autoridades aliadas. Muchos encontraron toda la colaboración que podían desear por parte de miembros del gobierno, el Ejército, la Iglesia católica y otros estamentos influyentes de la España franquista, ${ }^{27}$ lo que para Adalberto de Baviera, el primer embajador de la RFA en Madrid, constituyó un auténtico quebradero de cabeza y uno de los problemas más espinosos de su misión en Madrid. ${ }^{28}$

A través de la labor cultural, el gobierno alemán trató de ofrecer una imagen renovada de su país, desligada del pasado nazi e identificada con los valores democráticos de la RFA. Para ello fue decisivo que las instituciones culturales alemanas en España - como el Instituto Arqueológico Alemán, la Sociedad Görres, o los colegios alemanes- que habían cerrado sus puertas en 1945 las pudieran reabrir paulatinamen-

24 ASCHMANN, Birgit: "La República Federal de Alemania y la imagen de Alemania en España, 1945-1963”, Ayer, núm. 69 (2008), pp. 129-154.

25 Despacho de Welck al Auswärtiges Amt, 22 de agosto de 1958, "Fragen betreffend die Legion Condor und die Blaue Division“, Politisches Archiv des Auswärtigen Amtes (PAAA), 206/76.

26 El título en la traducción española diluía la responsabilidad alemana entre interrogantes. JASPERS, Karl: ¿Es culpable Alemania?, Madrid, [s.e.], 1948. Sobre la percepción de los juicios a los criminales de guerra alemanes, véase FERNÁNDEZ DE LA MORA, Gonzalo, "Las aporías de Nuremberg”, Arbor, vol. XVIII, n 64 (abril 1951), pp. 535-562.

27 COLLADO SEIDEL, Carlos: España, refugio nazi, Madrid, Temas de Hoy, 2005.

28 BAYERN, Adalbert Prinz von: Erinnerungen 1900-1956. München, Langen Müller, 1991, pp. 539-540. 
te a lo largo de los años cincuenta. ${ }^{29}$ Otras, como los Institutos Goethe de Madrid y Barcelona, eran creaciones de nuevo cuño. Apoyado en estos anclajes institucionales, el liderazgo cultural alemán pudo entonar un breve canto del cisne en España de la segunda posguerra mundial, antes de ser desplazado -desde mediados de la década- por la fuerza avasalladora de la ciencia y la cultura anglosajonas, es decir, ante todo estadounidense..$^{30}$

Quedaba un cierto prestigio cultural que se hacía muy patente en los colegios alemanes como la Deutsche Schule de la barcelonesa calle Moià a la que Jordi Pujol había acudido de 1935 a 1945 (con una breve interrupción en 1937). Enviado por un padre "bolsista de Barcelona que quería dar un futuro sólido a su hijo" y "anglófilo declaradamente antinazi" a un centro donde cada mañana desde 1939 los profesores comenzaban la jornada con un “¡Heil Hitler!” y “¡Arriba España!”, Pujol se formó en su infancia y primera juventud en este colegio debido a "la admiración que [su progenitor] sentía por la cultura y la técnica germánicas" por un lado, y al "anticlericalismo que por entonces profesaba" por otro, ya que consideró que este centro ofrecía la mejor calidad educativa, una vez descartadas todas las escuelas religiosas. ${ }^{31}$ Era el mismo colegio al que Esther Tusquets, alumna de 1941 a 1945, regresó tras su reapertura en 1950 en una torre del barrio barcelonés de Vallcarca, reconvertido en Colegio San Alberto Magno, con un "ficticio director español como tapadera, ya que la administración no autorizaba otra cosa", y con un nombre que pretendía "ahuyentar sospechas de falta de religiosidad o de connivencia con los protestantes". El colegio mantenía la coeducación y el laicismo, "excesivamente avanzado e incluso moralmente peligroso para una parte de la burguesía catalana del momento", así como el un buen nivel académico general. ${ }^{32}$

¿Cómo comprender el fracaso último de la cultura y la ciencia alemanas, evidenciado en la derrota bélica y en la inhumanidad de los lager nazis? Uno de los primeros esfuerzos de posguerra por explicar "Alemania" a los lectores españoles fue el emprendido por José Luis Pinillos desde la perspectiva de la psicología colectiva a través de su artículo "Ideas para una intelección de Alemania", publicado en Arbor en 1950.

29 SANZ DÍAZ, Carlos: "El papel de la política cultural en las relaciones hispano-alemanas, 1949-1966", Ayer, núm. 69 (2008), pp. 155-185. Véase también RUIZ ESCUDERO, Inés: Franco y Adenauer. La diplomacia cultural hispano-germana en los años cincuenta. Valladolid, Universidad, 2015.

30 Como señala SOTELO, Ignacio: "Consideraciones preliminares sobre el diálogo cultural entre España y Alemania desde una perspectiva europea”, I Encuentro. Diálogo Cultural Hispano-Alemán en el marco de la política cultural europea, Madrid, Fundación Santillana, 1988, pp. 5-18, esp. p. 15. Véase también RADERS, M., y SCHILLING, M. L. (eds.): Deutsch-spanische Literatur- und Kulturbeziehungen. Rezeptionsgeschichte/ Relaciones hispano-alemanas en la literatura y la cultura. Historia de la recepción, Madrid, Ediciones del Orto-Departamento de Filología Alemana UCM, 1995; VEGA CERNUDA, Miguel Ángel y WEGENER, Hennig (eds.): España y Alemania. Percepciones mutuas de cinco siglos de historia, Madrid, Editorial Complutense, 2002; BADER, Wolfgang, y OLMOS, Ignacio. (eds.): Die deutsch-spanischen Kulturbeziehungen im europäischen Kontext: Bestandaufnahme, Probleme, Perspektiven, Frankfurt am Main, Vervuert, 2004.

31 PUJOL, Jordi: Memorias (1930-1980): historia de una convicción, Barcelona, Destino, 2008.

32 TUSQUETS, Esther: Habiamos ganado la guerra. Barcelona, Bruguera, 2007, pp. 104, 151, 55 y 153-155. Sobre las escuelas alemanas en España tras la Segunda Guerra Mundial véase COLLADO SEIDEL, Carlos: "Ende und Neuanfang der Deutschen Schulen in Spanien nach 1945", en Werner Altmann y Ursula Vences (Hrsg.), Por España y el mundo hispánico. Festschrift für Walther L. Bernecker, Berlin, edition tranvía/Verlag Walter Frey, 2007, pp. 126-142. 
Tratando de diseccionar la "forma de ser alemana", Pinillos detectaba en los alemanes como colectividad una serie de rasgos característicos, ${ }^{33}$ comenzando por la (supuesta) tendencia al belicismo y al militarismo, es decir "la presencia de una cierta propensión al entusiasmo bélico indiferenciado - frecuente también en España - que se agota en la exaltación de los valores volitivos". Junto con ello, el voluntarismo o primacía de la voluntad en todos los ámbitos de la existencia; el formalismo, es decir "la acentuación del amor a las formas ordenadas en canto tales, [que] ha hecho de la máquina social germánica un instrumento admirable"; el sentido de religación con la Naturaleza, la particular vivencia del paisaje y el clima germánicos, que determinarían un estilo particular de pensamiento muy atento a la complejidad y al matiz; y por último, lo que Pinillos llama la "tendencia a la desintegración", es decir, la presunta capacidad del carácter germánico para separar las diferentes facetas de la vida, que pueden coexistir a pesar de la aparente contradicción: lo racional y lo sentimental, "lo científico y lo romántico, lo brutal y lo sentimental, la posibilidad de que alguien escriba poesías y mande un campo de liquidación". ${ }^{34}$

Los alemanes eran, en suma, para Pinillos, "los centauros de la modernidad", montados en las bicicletas que suplían las carencias de los transportes de posguerra y que les daban el aspecto de seres mitólogicos, a la vez proyectados hacia el futuro y anclados en algunos elementos más propios de un mundo arcaico. Se trataba de una clave de comprensión dual que hundía sus raíces -aunque el autor no lo hacía explícito- en debates culturales anteriores, rastreables al menos hasta la polémica entre aliadófilos y germanófilos, que cristalizó en la idea de dos Alemanias antitéticas: una filosófica, universalista, humanitaria y pacífica, un pueblo de poetas, músicos y pensadores, la Alemania de Kant, de Fichte, Beethoven y Schopenhauer; y una Alemania brutal y ambiciosa, la Germania de los Kaisers y de sus mariscales, que posteriormente se encarnaría en Reich de Hitler y los campos de concentración. ${ }^{35}$

Un intento de síntesis o reconciliación de contrarios lo ofrecería a mediados de los cincuenta José Luis López Aranguren en un ensayo sobre la imagen de Alemania en España. ${ }^{36}$ Aranguren partía de la "rara unanimidad en la imagen española de Alemania", una imagen cargada de tópicos pero fuertemente admirativa y llena de "simpatía" y buena predisposición, que se basaba en la "ley de la complementariedad: el español admira en el alemán virtudes de las más de las cuales [sic] él carece: orden, disciplina y perfecta organización, tesón y trabajo, elevado nivel científico, técnico e industrial; asimismo la profundidad espiritual y la seriedad moral. También le admira por su sorprendente resurgimiento económico y por su alto nivel medio de vida." 37 Aranguren no veía más que buenas perspectivas para un acercamiento hispano-alemán en diversos "planos de inteligencia", de lo comercial a lo político sin olvidar lo cultural: en lo tocante a la cultura religiosa, pese al atractivo del catolicismo francés, la jerarquía de la Iglesia española prefería los centros de formación alemanes para

33 Asumía el autor como propia la idea romántica de que "las colectividades tienen determinadas maneras de ser e ideas propias por las que rigen" y que estas constituyen "el espíritu objetivo de las naciones". PINILLOS, José Luis: "Ideas para una intelección de Alemania", Arbor, vol. XVII, no 60 (1950), pp. 385-405, esp. Pp. 385-386.

34 Ibídem, pp. 403-404.

35 DÍAZ PLAJA, Fernando: Francófilos y germanófilos: los españoles en la Guerra europea, Barcelona, Dopesa, 1973.

36 LÓPEZ ARANGUREN, José Luis: “Imagen española de Alemania”, Dokumente (Colonia), 1 (1957), reimpreso en Revue de Psichologie des Peuples (Le Havre), tercer trimestre de 1964, e inserto en La juventud europea y otros ensayos, Barcelona, Seix Barral, 1963 (3 ${ }^{\mathrm{a}}$ ed.), pp. 175-194.

37 Ibidem, p. 188. 
enviar a formarse a seminaristas y a sacerdotes jóvenes; en la vertiente de la cultura laica, afirmaba, a pesar de la supremacía de EE.UU. en muchos ámbitos del saber, "los jóvenes graduados españoles por las Universidades civiles siguen prefiriendo, para completar sus estudios, las Universidades alemanas -Friburgo de Brisgovia, Heidelberg, Munich, etc.- a las de otros países", ya que "admiración, simpatía predisposición favorable, todo les empuja a ello". ${ }^{38}$

\section{Coda}

El optimismo de Aranguren, lo sabemos hoy, no se ajustaba a la realidad. Aunque en algunas ramas del saber la ampliación de estudios en Alemania siguió siendo preceptiva, la posición del país como referente cultural en España, y su papel como puerta de acceso a la gran corriente de la cultura europea estaba en fase declinante a mediados de los años cincuenta.

La mirada retrospectiva arroja sobre este periodo una cierta luz crepuscular, como la que ilumina las últimas giras de conferencias - todas ellas enormemente exitosas y concurridas - de Ortega y Gasset en Alemania: en Darmstadt, Stuttgart y Berlín en 1949, Múnich en 1951, en Hannnover, Múnich y Hamburgo en 1953, en Bonn en 1954... Del mismo modo que el sueño orteguiano de trasladar a Múnich el Instituto de Humanidades, reconvertido en centro europeo para irradiar desde la capital bávara a todo el Viejo Continente, se quedaría en un proyecto nunca realizado, ${ }^{39}$ Alemania fue cada vez menos esa puerta por la que la cultura española se asomaba a Europa y al mundo.

\section{Bibliografía}

Acerete De La Corte, Eduardo: “España medieval, Alemania contemporánea. El tránsito historiográfico de Juan José Carreras Ares", en Juan José Carreras Ares, De la España medieval a la Alemania contemporánea. Primeros escritos (1953-1968), Zaragoza, Instituto "Fernando el Católico"(CSIC) y Excma. Diputación de Zaragoza, 2014 (edición de Eduardo Acerete de la Corte), pp. V-CIX.

Bader, Wolfgang, y Olmos, Ignacio. (eds.): Die deutsch-spanischen Kulturbeziehungen im europäischen Kontext: Bestandaufnahme, Probleme, Perspektiven, Frankfurt am Main, Vervuert, 2004.

Barral, Carlos: Años de penitencia. Barcelona, Tusquets, 2001.

Bayern, Adalbert Prinz Von: Erinnerungen 1900-1956. München, Langen Müller, 1991.

Capella, Juan-Ramón: La práctica de Manuel Sacristán. Una biografía política. Madrid, Trotta, 2005.

Capella, Juan-Ramón: “Manuel Sacristán. Esbozo de una biografía política”, en: López Amal, S. y Vázquez Álvarez, I. (eds.): El legado de un maestro. Homenaje a Manuel Sacristán, Madrid, FIM, 2007, pp. 31-39.

38 Ibídem, p. 194.

39 GRACIA, Jordi: José Ortega y Gasset, pp. 616-639. 
Aschmann, Birgit: "La República Federal de Alemania y la imagen de Alemania en España, 1945-1963”, Ayer, no 69 (2008), pp. 129-154.

Bader, Wolfgang y Olmos, Ignacio (Hrsg.): Die deutsch-spanischen Kulturbeziehungen im europäischen Kontext. Bestandaufnahme, Probleme, Perspektiven. Frankfurt am Main,Vervuert, 2004.

Collado Seidel, Carlos: España, refugio nazi, Madrid, Temas de Hoy, 2005.

Collado Seidel, Carlos: "Ende und Neuanfang der Deutschen Schulen in Spanien nach 1945”, en Werner Altmann y Ursula Vences (Hrsg.), Por España y el mundo hispánico. Festschrift für Walther L. Bernecker, Berlin, edition tranvía/Verlag Walter Frey, 2007, pp. 126-142.

Díaz Plaja, Fernando: Francófilos y germanófilos: los españoles en la Guerra europea, Barcelona, Dopesa, 1973.

Fernández de La Mora, Gonzalo: “Las aporías de Nuremberg”, Arbor, vol. XVIII, nº 64 (abril 1951), pp. 535-562.

Fernández de La Mora, Gonzalo: Río arriba. Memorias, Barcelona, Planeta, 1995.

Forcadell Álvarez, Carlos (ed.): Razones de historiador. Magisterio y presencia de Juan José Carreras, Zaragoza, Institución "Fernando el Católico", 2009.

González Cuevas, Pedro Carlos: La razón conservadora: Gonzalo Fernández de la Mora, una biografía político-intelectual. Madrid, Biblioteca Nueva, 2015.

Gracia, Jordi: José Ortega y Gasset, Madrid, Taurus, 2014.

Jaspers, Karl: ¿Es culpable Alemania?, Madrid, [s.e.], 1948.

Kent, Conrad, Wolber, Thomas K. y Hewitt, Camron M.K. (eds.): The Lion and the Eagle. Interdisciplinary Essays on German-Spanish Relations over the Centuries, New York, Berghahn Books, 2000.

López Aranguren, José Luis: "Imagen española de Alemania", Dokumente (Colonia), 1 (1957), reimpreso en Revue de Psichologie des Peuples (Le Havre), tercer trimestre de 1964, e inserto en La juventud europea y otros ensayos, Barcelona, Seix Barral, 1963 (3 ${ }^{\mathrm{a}}$ ed.), pp. 175-194.

López García, José Antonio: "La presencia de Carl Schmitt en España”, Revista de Estudios Políticos (Nueva Época), núm. 91 (1996), pp. 139-186.

López Zúñiga, Miguel Á.: “Manuel Sacristán Luzón: una vida vinculada al marxismo”, Economía Informa, núm. 346 (mayo-junio 2007), pp. 87-100.

Núñez Seixas, Xosé-Manoel: La sombra del César. Santiago Montero Díaz, una biografía entre la nación y la revolución. Granada, Comares, 2012.

Ortega y Gasset, José: Meditación de Europa. Madrid, Revista de Occidente, 1960.

Peiró, Ignacio: "Las metamorfosis de un historiador: el tránsito hacia el contemporaneísmo de José María Jover Zamora", Revista de Historia Jerónimo Zurita, núm. 82 (2007), pp. 175-234.

Pinillos, José Luis: “Ideas para una intelección de Alemania”, Arbor, vol. XVII, nº 60 (1950), pp. 385-405. 
Presas i Puig, Albert: "La inmediata posguerra y la relación científica y técnica con Alemania", en Romero De Pablos, Ana y Santesmases Navarro de Palencia, María Jesús (coord.): Cien años de política cientifica en España, Bilbao, Fundación BBVA, 2008, pp. 173-210.

Pujol, Jordi: Memorias (1930-1980): historia de una convicción, Barcelona, Destino, 2008.

Raders, M., y Schilling, M. L. (eds.): Deutsch-spanische Literatur- und Kulturbeziehungen. Rezeptionsgeschichte/ Relaciones hispano-alemanas en la literatura y la cultura. Historia de la recepción, Madrid, Ediciones del Orto-Departamento de Filología Alemana UCM, 1995.

Rebok, Sandra (ed.): Traspasar fronteras. Un siglo de intercambio cientifico entre España y Alemania / Über Grenzen hinaus. Ein Jahrhundert deutsch-spanische Wissenschaftsbeziehungen. Madrid: Consejo Superior de Investigaciones Científicas / Deutscher Akademischer Austauschdienst, 2010

Romero, Ana: “Un viaje de José María Otero Navascués. Los inicios de la investigación nuclear en España", Arbor, vol. 167, núm. 659-660 (2000), pp. 509-525.

Ruiz Escudero, Inés: Franco y Adenauer. La diplomacia cultural hispano-germana en los años cincuenta. Valladolid, Universidad, 2015.

Sanz Díaz, Carlos: "El papel de la política cultural en las relaciones hispano-alemanas, 19491966”, Ayer, núm. 69 (2008), pp. 155-185.

Saralegui, Miguel: Carl Schmitt, pensador español. Madrid, Trotta, 2016.

Sotelo, Ignacio: "Consideraciones preliminares sobre el diálogo cultural entre España y Alemania desde una perspectiva europea”, I Encuentro. Diálogo Cultural Hispano-Alemán en el marco de la política cultural europea, Madrid, Fundación Santillana, 1988, pp. 5-18.

Tusquets, Esther: Habiamos ganado la guerra. Barcelona, Bruguera, 2007.

Vega Cernuda, Miguel Ángel y Wegener, Hennig (eds.): España y Alemania. Percepciones mutuas de cinco siglos de historia. Madrid, Editorial Complutense, 2002. 